\title{
Late Charge Pada Syariah Card Dalam Perspektif Islam
}

\author{
Khoiri ${ }^{1}$ \\ STAIN Bengkalis \\ Email:rie_khay@yahoo.com
}

\begin{abstract}
This study investigated the law of late change in the Fatwa of the National Sharia Council (DSN) No. 54/DSN-MUI/X/2006 on Sharia Cards). The results of the study found that late charge in sharia cards in accordance with the National Sharia Council Fatwa (DSN) No. 54/DSN-MUI/X/2006 on Sharia Cards) was obtained with a record of late charge as a sanction or punishment based on the principle of $t a^{\prime} z i r$ that is submit and sake of improvement in order to make its customers more disciplined in carrying out their obligations and the money resulting from the fine was not claimed as the income of the card issuer but was intended as a social fundand the nominal amount based on mutual agreement rather than unilateral.
\end{abstract}

Keywords: Late Charge, Syariah Card, Islam

\section{Abstrak}

Penelitian ini bertujuan untuk mengetahui hukum denda keterlambatan (late chage) dalam Fatwa Dewan Syariah Nasional (DSN) Nomor 54/DSN-MUI/X/2006 Tentang Syariah Card). Hasil penelitian ditemukan bahwa denda keterlambatan (late charge) dalam syariah card sesuai dengan Fatwa Dewan Syariah Nasional (DSN) Nomor 54/DSN-MUI/X/2006 Tentang Syariah Card) diperbolehkan dengan catatan bahwwa denda keterlambatan (late charge) adalah sanksi atau hukuman yang didasarkan pada prinsip ta'zir yaitu bersifat menyerahkan dan demi perbaikan serta bertujuan agar nasabahnya lebih disiplin dalam melaksanakan kewajibannya dan uang hasil dari denda tidak diklaim sebagai pendapatan penerbit kartu tetapi diperuntukkan sebagai dana sosial,dan besar nominalnya juga berdasarkan kesepakatan bersama bukan sepihak.

Kata Kunci: Late Charge, Syariah Card, Islam

\section{A. Pendahuluan}

Syariah card adalah kartu yang berfungsi seperti kartu kredit yang hubungan hukum (berdasarkan sistem yang sudah ada) antara para pihak berdasarkan prinsip syariah ${ }^{2}$.Meskipun syariah card menggunkan prinsip syariah tetapi apabila terjadi keterlambatan pembayaran, pemegang kartu tetap dikenakan denda

1 Dosen Sekolah Tinggi Agama Islam Negeri (STAIN) Bengkalis dan Candidat Doktor Universitas Islam Negeri Sutan Syarif Kasim Riau

${ }^{2}$ Lihat Fatwa Dewan Syariah Nasional Nomor 54 Tahun 2006 Tentang Syariah Card, hal 10 
keterlambatan sebagaimana tertuang dalam Fatwa Dewan Syariah Nasional (DSN) Nomor 54/DSN-MUI/X/2006 Tentang Syariah Card).

Denda keterlambatan (late charge) adalah denda yang diberikan oleh penerbit kartu kepada pemegang kartu dikarenakan keterlambatan pembayaran yang akan diakui seluruhnya sebagai dana sosial ${ }^{3}$.Menurut Penulis denda keterlambatan seperti ini sudah termasuk riba nasiah. Riba nasiah adalah adanya perbedaan, perubahan, atau tambahan antara yang diserahkan saat ini dan yang diserahkan saat kemudian 4 .

\section{B. Landasan Teori}

Syariah card sering disebut dengan credit card (bahasa Inggris) yang berarti kartu kredit, dimana dalam kamus bahasa Indonesia kartu berarti kertas tebal yang segi empat bangunnya dan kredit adalah pinjaman ${ }^{5}$.Sedangkan dalam bahasa Arab istilah kartu kredit sering disebut dengan bithaqah i'timan atau bithaqah Al-iqrad. Bithaqah dalam kamus bahasa Arab berarti kertas atau kartu, i'timan secara bahasa berarti kondisi aman dan saling percaya, dan iqradh dalam bahasa Arab berarti peminjaman 6 .

Jadi dapat dipahami bahwa syariah card adalah kartu kredit yang diberikan oleh penerbit kartu dalam hal ini adalah pihak bank syariah kepada pemegang kartu dalam hal ini adalah nasabah dengan berdasarkan prinsip syariah.

Adapun prinsip-rinsip yang digunakan dalam transaksi syariah card yaitu: ${ }^{7}$

\section{Akad Kafalah}

Lafadh/kata al-kafalah merupakan masdar (kata awal) yang fiil madhinya ialah kafala dan fi'il mudhori'nya yakfulu, yang secara umum berarti beban yakni hamlun.Adapun pengertian al-kafalah menurut istilah ahli hukum Islam (syara'), secara umum ialahpenggabungan tanggungan yang satu kepada yanglain tentang hak yang saling menuntut"8.

Kafalah dalam hal ini penerbit kartu adalah penjamin (kafil) bagi pemegang kartu terhadap merchant atas semua kewajiban bayar (dayn) yang

${ }^{3}$ Ibid.,

${ }^{4}$ Muhamad Syakir Sula,dan Aaly, FIIS, Asuransi Syariah, (Jakarta: Gema Insani, 2004), hal. 51

5S. Wojowasito, Kamus Besar Bahasa Indonesia, (Malang: CV. Pengarang, 1999), hal 154-194.

${ }^{6}$ Munawir AF dan Adib Bisri, Kamus Al-Bisri Indonesia-Arab Arab-Indonesia, (Surabaya: Pustaka Prograssif, 1999), hal 36

${ }^{7}$ Fatwa Dewan Syariah Nasional Nomor 54 Tahun 2006 Tentang Syariah Card, hal 10 hal. 223

${ }^{8}$ Syeh Qosim al-Kounsy, Anis al-Fuqoha Muassanah al Kutub Assqofiyah, (Jeddah: Dar al-Wifa, t.t), 
timbul dari transaksi antara Pemegang Kartu dengan Merchant, dan/atau penarikan tunaidari selain bank atau ATM bank Penerbit Kartu. Ataspemberian Kafalah, penerbit kartu dapat menerima fee (ujrahkafalah).

2. Akad Qardh

Istilah al-qardh secara lughawi (etimologi) berarti (terputus). Harta yang dihutangkan kepada pihak lain dinamakan qardh karena ia terputus dari pemiliknya 9. Menurut istilah (terminologinya), Qardh sesuai dengan definisi yang berkembang di kalangan fuqaha adalah akad penyerahan (pemilikan) harta al-misliyat kepada orang lain untuk ditagih pengembaliannya, atau dengan pengertian lain, suatu akad yang bertujuan untuk menyerahkan harta misliyat kepada pihak lain untuk dikembalikan yang sejenis dengannya" 10 .

Dalam hal ini penerbit kartu adalah pemberi pinjaman(muqridh) kepada pemegang kartu (muqtaridh) melaluipenarikan tunai dari bank atau ATM bank Penerbit Kartu.

\section{Akad Ijarah}

Al Ijarah adalah akad pemindahan hak guna atas barang atau jasa, melalui pembayaran upah sewa, tanpa diikuti dengan pemindahan kepemilikan (ownership/milkiyah) atas barang itu sendiri11.Dalam hal ini Penerbit Kartu adalah penyedia jasasistem pembayaran dan pelayanan terhadap Pemegang Kartu.Atas Ijarah ini, Pemegang Kartu dikenakan membership fee.12

\section{Metode Penelitian}

Penelitian ini merupakan penelitian kepustakaan (library research), suatu kajian yang menggunakan literatur kepustakaan dalam hal ini bahan hukum primernya adalah Fatwa Dewan Syariah Nasional (DSN) Nomor 54/DSNMUI/X/2006 Tentang Syariah Card).Kemudian ditambah dengan bahan hukum skunder berupa kitab-kitab, buku, jurnal dan lainnya yang berhuybungan dengan pembahasan.Dalam menganalisis, penulis menggunakan metode deskripsi dan conten analisis yaitu sebuah sistem penulisan dengan dengan cara mendeskripsikan

${ }^{9}$ Sayyid Sabbiq, Fiqh As-Sunnah, (Mesir:Darrul Fikr, Mesir, tt), Juz. III, hal., 182

10 Wahbah al-Zuhaily, Al-Fiqh al-Islamiy Wa adillatuhu, Juz IV, hlm. 720

11 Muhammad Syafi'i Antonio, Bank Syari'ah dari Teori ke Praktek, (Jakarta: Gema Insani, 2001), Cet. I., hal. Hal.117

12Fatwa Dewan Syariah Nasional Nomor 54 Tahun 2006 Tentang Syariah Card, hal 10 
realitas fenomena sebagai mana adanya yang dipilihdari persepsi subyek ${ }^{13}$. Setelah itu mengidentifikasi, mempelajari dan kemudian melakukan analisis terhadap apa yang diselidiki ${ }^{14}$.

\section{Hasil dan Pembahasan}

Ada dua catatan penting yang perlu diperhatikan dari Fatwa Dewan Syariah Nasional (DSN) Nomor 54/DSN-MUI/X/2006 Tentang Syariah Card)yang memperbolehkan dalam hal ini adalah pihak bank menerapkan denda keterlambatan (late charge) yaitu:

1. Denda keterlambatan (late charge) adalah sanksi atau hukuman yang didasarkan pada prinsip ta'zir yaitu bersifat menyerahkan dan demi perbaikan serta bertujuan agar nasabahnya lebih disiplin dalam melaksanakan kewajibannya.

Denda merupakan salah satu jenis dari hukuman ta'zir.Ta'zir menurut bahasa adalah $t a^{\prime} d i b$, artinya memberi pelajaran.Ta'zir juga diartikan dengan Ar-Raddu Wal Man'u, yang artinya menolak dan mencegah ${ }^{15}$.At-ta'zir adalah larangan, pencegahan, menegur, menghukum, mencela dan memukul.Hukuman yang tidak ditentukan (bentuk dan jumlahnya), yang wajib dilaksanakan terhadap segala bentuk maksiat yang tidak termasuk hudud dan kafarat, baik pelanggaran itu menyangkut hak Allah Swt. maupun hak pribadi ${ }^{16}$.

Dalam ta'zir, hukuman itu tidak ditetapkan dengan ketentuan (dari Allah Swt. dan Rasulnya Saw.), dan Qadhi diperkenankan untuk mempertimbangkan baik bentuk hukuman yang akan dikenakan maupun kadarnya. Pelanggaran yang dapat dihukum dengan metode ini adalah yang mengganggu kehidupan dan harta orang serta kedamaian dan ketentraman masyarakat.Hukuman itu dapat berupa cambukan, kurungan penjara, denda, peringatan dan lain-lain ${ }^{17}$.

Ta'zir (hukuman yang tidak ada aturannya dalam Syara') adalah hukuman yang bersifat mendidik seperti memenjara dan memukul yang tidak sampai melukai, tidak boleh melakukan ta'zir dengan mencukur jenggot ataupun

\footnotetext{
13 Seojono dan Abdurrahman, Metode Penelitian (Suatu Pengantar dan Penerapan), (Jakarta: Rieneka Cipta,1999), Hal. 23

${ }^{14}$ Noeng Muhaadjir, Metodologi Penelitian Kualitatif, (Yogysksrta: Rake Sarasin, 1991), Hal. 49

${ }^{15}$ Ahmad Wardi Muslich, Hukum Pidana Islam,(Jakarta: Sinar Grafika, 2005), hal. xii

${ }^{16}$ Abdul Aziz Dahlan, Ensiklopedi Hukum Islam, (Jakarta: Ichtiar Baru Van Hoeve, 2003), Cet. IV, hal. 1771

${ }^{17}$ Abdur Rahman I Doi, Tindak Pidana Dalam Syariat Islam, (Jakarta: PT.Rineka Cipta, hal. 14
} 
Khoiri, Muklisin :Late Charge Pada Syariah ...

memungut uang (denda).Kaum muslimin yang harus melaksanakan ta'zir dengan memungut uang, mengikuti pendapat Imam Malik yang membolehkan.Sedangkan Imam Syafi'i dan ulama pengikut Imam Syafi'i tidak ada satupun yang membolehkan memungut denda uang.Dalam sebagian fatwa Ibnu 'Alan bahwa pendapat yang membolehkan pemungutan uang tersebut sesuai dengan pendapat Imam Malik. Sebagian dasarnya adalah pengerusakan Khalifah Umar terhadap rumah Sa'ad, ketika ia lari bersembunyi dari pengawasannya dan juga pembakaran olehnya terhadap rumah-rumah penjual minuman keras $^{18}$.

Secara garis besar hukuman ta'zir dapat dikelompokkan menjadi empat kelompok yaitu (1) Hukuman ta'zir yang mengenai badan, seperti hukuman mati dan jilid (dera), (2) Hukuman yang berkaitan dengan kemerdekaan seseorang, seperti hukuman penjara dan pengasingan, (3) Hukuman ta'zir yang berkaitan dengan harta, seperti denda, penyitaan/perampasan harta, dan penghancuran barang dan (4) Hukuman-hukuman lain yang ditentukan oleh ulil amri demi kemaslahatan umum ${ }^{19}$.

Denda keterlambatan ini termasuk kelompok yang ketiga yaitu hukuman ta'zir yang berkaitan dengan harta. Para ulama berbeda pendapat tentang dibolehkannya hukuman ta'zir dengan cara mengambil harta. Menurut Abu Hanifah, hukuman ta'zir dengan cara mengambil harta tidak dibolehkan. Pendapat ini diikuti oleh muridnya, yaitu Muhammad Ibn Hasan, tetapi muridnya yang lain yaitu Imam Abu Yusuf membolehkannya apabila dipandang membawa maslahat.Pendapat ini diikuti oleh Imam Malik, Imam Syafi'i, dan Imam Ahmad Ibn Hanbal20.

Pada intinya ialah untuk mempertahankan eksistensi dari penerbit kartu kredit syariah yang merupakan lembaga komersial.Maka dapat diketahui bahwa denda keterlambatan (late charge) dibutuhkan untuk diterapkan dalam kartu kredit syariah, guna mendisiplinkan pemegang kartu kredit syariah dalam membayar utang.Hal ini sudah sejalan dengan kaidah:

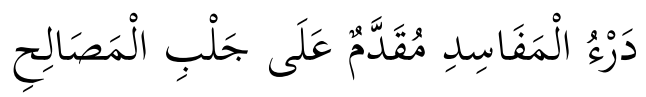

18 Djamaludin Miri, Ahkamul Fuqaha, (Surabaya: LTN NU Jawa Timur, 2004), hal. 36

${ }^{19}$ Ahmad Wardi Muslich, Op. Cit., hal. 258

${ }^{20}$ Ibid, hal.265-267 
Khoiri, Muklisin :Late Charge Pada Syariah ...

Maksudnya: "Menghindarkan kerusakan (kerugian) harus didahulukan (diprioritaskan) atas mendatangkan kemaslahatan '21.

Kerugian yang dimaksud disini adalah dengan keterlambatan atau macetnya pembayaran pemegang kartu syariah carddalam membayar dari hasil penarikan bisa berpengaruh dan berdampak kepada kesehatan keuangan bank itu sendiri.Mungkin jika yang menggunakan syariah card kemudian menunggak kewajibannya hanya satu atau dua orang saja mungkin tidak sangat berpengaruh apalagi penarikannya kecil dan sedikit.Namun jika penarikannya banyak dan kewajiban membayar menunggak sehingga sampai milyaran atau triliunan, hal ini bisa mempengaruhi terhadap kesehatan bank tersebut, bahkan bisa membuat bank tersebut pailit (bangkrut/kolap) atau bisa-bisa tutup.

2. Uang hasil dari denda tidak diklaim sebagai pendapatan penerbit kartu tetapi diperuntukkan sebagai dana sosial,dan besar nominalnya juga berdasarkan kesepakatan bersama, tidak hanya berasal dari pihak yang mempunyai piutang saja, maka denda keterlambatan (late charge) telah sesuai dengan hukum islam, sehingga diperbolehkan untuk diterapkan dalam kartu kredit syariah.

Denda keterlambatan tersebut harus diakui sebagai dana sosial. Sumber danaqarḍ \&qardul hasan berasal dari eksternal dan internal. Sumber dana eksternal meliputi dana qard yang diterima bank syariah dari pihak lain (misalnya dari sumbangan, infak, shadaqah, dan sebagainya), dana yang disediakan oleh para pemilik bank syariah dan hasil pendapatan non-halal. Sumber dana internal meliputi hasil tagihan pinjaman. Untuk lebih jelasnya dana sosial itu bersumber dari ${ }^{22}$ :

1. Infaq dan Shadaqahyaitu dana yang diterima dari pihak luar atau dari rekening nasabah atas permintaan nasabah.

2. Sumbangan (hibah) yaitu dana yang diterima dari nasabah atas permintaan nasabah dan tanpa paksaan diperuntukan guna kepentingan sosial.

3. Denda yang dimaksud disini ialah kompensasi yang wajib dilakukan oleh nasabah karena melanggar aturan Bank. Seperti, terlambat atau tidak melunasi pinjaman.

${ }^{21}$ Lihat, fatwa Dewan Syariah Nasional (DSN) Nomor 54/DSN-MUI/X/2006 tentang Syariah Card

${ }^{22}$ Http://fis.uii.ac.id/images/la-riba-vol2-no2-2008-08-hermawan.pdf, diakses pada tanggal 16 Agustus 2020 pukul $14.00 \mathrm{Wib}$ 
4. Pendapatan Non Halal yaitu aplikasi sumber dana kebajikan berupa pendapatan non halal pada perbankan syariah berasal dari penerimaan jasa giro dari bank Cabang. Dengan demikian Bank Syariah terkadang mendapat keuntunagan yang berupa bunga yang dialokasikan kepada konvensional atau penerimaan lainnya yang tidak dapat dihindari dalam kegiatan operasional bank.

Dana qarḍ \&qarḍl hasan tidak masuk dalam laporan neraca karena dana tersebut termasuk dalam pembiayaan atau pendanaan yang digunakan oleh suatu perusahaan yang tidak menunjukan kewajiban pada neraca balance sheet financing). Sementara pendistribusian atau pendayagunaan danaqardh (qardhul hasan) hanya dialokasikan kepada warga atau masyarakat yang termasuk dalam golongan ekonomi lemah (dhu'afa).

\section{E. Kesimpulan}

Kesimpulan dari penelitian ini yaitu denda keterlambatan (late charge) dalam syariah card sesuai dengan Fatwa Dewan Syariah Nasional (DSN) Nomor 54/DSNMUI/X/2006 Tentang Syariah Card) dieprbolehkan dengan catatan denda keterlambatan (late charge) adalah sanksi atau hukuman yang didasarkan pada prinsip ta'zir yaitu bersifat menyerahkan dan demi perbaikan serta bertujuan agar nasabahnya lebih disiplin dalam melaksanakan kewajibannya dan uang hasil dari denda tidak diklaim sebagai pendapatan penerbit kartu tetapi diperuntukkan sebagai dana sosial,dan besar nominalnya juga berdasarkan kesepakatan bersama.

\section{DAFTAR PUSTAKA}

Abdul Aziz Dahlan, Ensiklopedi Hukum Islam, (Jakarta: Ichtiar Baru Van Hoeve, 2003), Cet. IV.

Abdur Rahman I Doi, Tindak Pidana Dalam Syariat Islam, (Jakarta: PT.Rineka Cipta), 2004.

Ahmad Wardi Muslich, Hukum Pidana Islam,(Jakarta: Sinar Grafika, 2005).

Djamaludin Miri, Ahkamul Fuqaha, (Surabaya: LTN NU Jawa Timur, 2004).

Fatwa Dewan Syariah Nasional Nomor 54 Tahun 2006 Tentang Syariah Card.

Http://fis.uii.ac.id/images/la-riba-vol2-no2-2008-08-hermawan.pdf, diakses pada tanggal 16 Agustus 2020 pukul 14.00 Wib. 
Khoiri, Muklisin :Late Charge Pada Syariah ...

Muhamad Syakir Sula,dan Aaly, FIIS, Asuransi Syariah, (Jakarta: Gema Insani, 2004).

Muhammad Syafi'i Antonio, Bank Syari'ah dari Teori ke Praktek, (Jakarta: Gema Insani, 2001), Cet. I.

Munawir AF dan Adib Bisri, Kamus Al-Bisri Indonesia-Arab Arab-Indonesia, (Surabaya: Pustaka Prograssif, 1999).

Noeng Muhaadjir, Metodologi Penelitian Kualitatif, (Yogysksrta: Rake Sarasin, 1991).

S. Wojowasito, Kamus Besar Bahasa Indonesia, (Malang: CV. Pengarang, 1999).

Sayyid Sabbiq, Fiqh As-Sunnah, (Mesir:Darrul Fikr, Mesir, tt), Juz. III.

Seojono dan Abdurrahman, Metode Penelitian (Suatu Pengantar dan Penerapan), (Jakarta: Rieneka Cipta,1999).

Syeh Qosim al-Kounsy, Anis al-Fuqoha Muassanah al Kutub Assqofiyah, (Jeddah: Dar alWifa, t.t).

Wahbah al-Zuhaily, Al-Fiqh al-Islamiy Wa adillatuhu, Juz IV. 